\title{
Capillary leak leading to shock in Kawasaki disease without myocardial dysfunction
}

\author{
Julia Natterer, ${ }^{1}$ Marie-Hélène Perez, ${ }^{1}$ Stefano Di Bernardo ${ }^{2}$ \\ ${ }^{1}$ Pediatric Intensive Care Unit; ${ }^{2}$ Pediatric Cardiology Unit, Department of Pediatrics, University Hospital and \\ University of Lausanne, CHUV, Switzerland
}

\begin{abstract}
Kawasaki disease is an acute vasculitis of childhood. Its clinical presentation is well known, and coronary artery aneurysms are classical complications. Shock and pleural or pericardiac effusion are rare presentations of the disease. In intensive care units, the disease may be mistaken for septic shock or toxic shock syndrome. Owing to the fact that immunoglobulin therapy improves the course of the disease, especially if given early, and thus the diagnosis should not be delayed.
\end{abstract}

Key words: Shock; intensive care; vasculitis

Received: 13 December 2010; Accepted: 7 August 2011; First published online: 21 September 2011

$\mathrm{K}$ AWASAKI DISEASE IS AN ACUTE, SYSTEMIC vasculitis of unknown aetiology, which mostly occurs in young children. In the absence of specific tests, the diagnosis is based on the presence of fever and at least four of the five well-known clinical features. Incomplete Kawasaki disease is defined by fever, two or three clinical features, and coronary disease on echocardiography.

Approximately $15 \%$ to $25 \%$ of untreated children develop coronary aneurysm. Owing to the fact that intravenous immunoglobulin treatment reduces the prevalence of coronary artery aneurysms to less than $5 \%,{ }^{1}$ patients should rapidly be treated. Aspirin is also part of the common treatment. Some patients remain febrile despite the treatment and should be treated again with intravenous immunoglobulin. ${ }^{2}$

Even though unusual, severe Kawasaki disease with pleural and pericardial effusion or patients mimicking toxic shock syndromes are possible but rare. ${ }^{3-5}$ Therefore, we report the cases of three children admitted to our paediatric intensive care unit for haemodynamic instability, respiratory failure, and neurological impairment due to Kawasaki disease.

Correspondence to: M.-H. Perez, Pediatric Intensive Care, Department of Pediatrics, University Hospital and University of Lausanne, CHUV, Rue du Bugnon 46, 1011 Lausanne, Switzerland. Tel: 00417955640 82; Fax: 004121 31437 59; E-mail: marie-helene.perez@chuv.ch

\section{Case reports}

Our institution is a tertiary centre in a region of about one million inhabitants. In our paediatric cardiology department, 15 to 20 cases of Kawasaki disease are diagnosed per year. Of these, five to eight are treated in our institution - small children, severe disease, or particular risk factors.

The first child was a 5.5-year-old girl, presenting first a classical Kawasaki disease. Cardiac echocardiography showed coronary hyperechogenicity and dilatation, with significant z-scores for the common truncus and the right coronary artery (Table 1). Systolic function was normal, with an ejection fraction of $63 \%$, and the echocardiography did not show any diastolic dysfunction. The girl was treated with intravenous immunoglobulin and aspirin on the fourth day of fever. Initially she improved for 3 days, but then she suddenly complained of abdominal pain. Her general and neurological state worsened. She was referred to the paediatric intensive care unit. Initial work-up showed increased C-reactive protein (241 milligrams per deciliter) and white blood cell count of $12.8 \times 10^{9}$ per litre $-29 \%$ of immature granulocytes - and decreased haemoglobin of 90 grams per litre and serum albumin of 19 grams per litre. There was no sign of other organ dysfunction, and troponin levels were slightly 
Table 1. Echocardiographic values.

\begin{tabular}{lllll}
\hline & $\begin{array}{l}\text { Anterior interventricular } \\
\text { coronary artery z-score }\end{array}$ & $\begin{array}{l}\text { Commun coronary } \\
\text { truncus z-score }\end{array}$ & $\begin{array}{l}\text { Right coronary } \\
\text { artery z-score }\end{array}$ & $\begin{array}{l}\text { Ejection fraction } \\
(\%)\end{array}$ \\
\hline Patient 1 & +1.6 & +3.26 & +4.4 & 63 \\
Patient 2 & +2.75 & +4.02 & +6.86 & 62 \\
Patient 3 & +3.6 & +4.97 & +2.32 & 73 \\
\hline
\end{tabular}

Table 2. Laboratory values at admission.

\begin{tabular}{|c|c|c|c|c|c|c|c|c|c|c|c|c|}
\hline & $\begin{array}{l}\text { GOT } \\
\text { (IU/l) }\end{array}$ & $\begin{array}{l}\text { GPT } \\
\text { (IU/1) }\end{array}$ & $\begin{array}{l}\text { Creatinin } \\
(\mu \mathrm{mol} / \mathrm{l})\end{array}$ & $\begin{array}{l}\text { BUN } \\
(\mathrm{mmol} / \mathrm{l})\end{array}$ & $\begin{array}{l}\text { CRP } \\
(\mathrm{mg} / \mathrm{dl})\end{array}$ & $\begin{array}{l}\text { WBC } \\
(\mathrm{g} / \mathrm{l})\end{array}$ & $\begin{array}{l}\text { Immature } \\
\text { granulocytes } \\
(\%)\end{array}$ & $\begin{array}{l}\mathrm{Hb} \\
(\mathrm{g} / \mathrm{l})\end{array}$ & $\begin{array}{l}\text { CK } \\
\text { (IU/l) }\end{array}$ & $\begin{array}{l}\text { CK-MB } \\
\text { (IU/l) }\end{array}$ & $\begin{array}{l}\text { Troponin } \\
(\mu \mathrm{g} / \mathrm{l})\end{array}$ & $\begin{array}{l}\text { Serum } \\
\text { albumin } \\
(\mathrm{g} / \mathrm{l})\end{array}$ \\
\hline Patient 1 & 54 & 44 & 78 & 8.3 & 468 & 12.8 & 29 & 90 & 231 & 47 & 0.09 & 19 \\
\hline Patient 2 & 46 & 44 & 57 & 8.7 & 164 & 3.5 & 57 & 83 & 140 & 12 & 0.74 & 18 \\
\hline Patient 3 & 31 & 79 & 32 & 14.1 & 372 & 21.4 & 39 & 75 & 21 & 30 & 0.03 & 26 \\
\hline
\end{tabular}

$\mathrm{BUN}=$ blood urea nitrogen $\mathrm{CK}=$ creatine kinase $\mathrm{CK}-\mathrm{MB}=$ creatine kinase-muscle and brain types; $\mathrm{CRP}=$ carbon-reactive protein;

GOT $=$ glutamic-oxaloacetic transaminase; $\mathrm{GPT}=$ glutamic-pyruvic transaminase; $\mathrm{Hb}=$ haemoglobin; $\mathrm{WBC}=$ white blood cell

elevated (Table 2). Chest X-ray and abdominal sonography revealed a large amount of ascites and pleural effusion. Mechanical ventilation was initiated for respiratory failure. After volume replacement with colloid and albumin, we had to start catecholamines because of persistent haemodynamic instability. A second dose of intravenous immunoglobulin was administered on the ninth day of fever - that is, 48 hours after admission to intensive care - and aspirin was continued. Owing to this unusual evolution mimicking septic shock, we also introduced antibiotics after complete septic work-up. Bacterial cultures were all negative. She gradually improved over 5 days after the second intravenous immunoglobulin dose. Catecholamines were stopped after 7 days. She was discharged from the paediatric intensive care unit after 8 days and from the hospital after another 7 days. Control echocardiography 2 months later showed no coronary aneurysm.

The second child was a 6-year-old boy, presenting with a cervical mass and fever, treated with amoxicillin and clavulanic acid without any improvement. He developed a rash after 4 days. After 7 days, his clinical state worsened, with the apparition of respiratory distress and rapidly progressive haemodynamic instability. Initial work-up showed haemoglobin (109 grams per litre), white blood cell count of $3 \times 10^{9}$ per litre ( $57 \%$ of immature granulocytes), C-reactive protein (220 grams per deciliter), and low serum albumin (18 grams per litre). There was only a slight elevation of liver enzymes and no sign of organ failure (Table 2). He was admitted to the intensive care with suspicion of either septic shock or toxic shock syndrome. Chest X-ray and abdominal sonography showed pleural and peritoneal effusion. Mechanical ventilation was initiated because of respiratory failure, and cardiovascular support with volume replacement and cathecholamines because of refractory hypotension. Antibiotic treatment was changed to vancomycin, imipenem, and amikacin; corticoid therapy was initiated because of capillary leak and shock. Owing to the fact that the clinical signs were indicative of Kawasaki disease - that is, fever, cervical mass, and rash - an echocardiography was performed the next day, showing coronary aneurisms with a positive z-score (Table 1). Systolic and diastolic functions were normal. The diagnosis of incomplete Kawasaki disease was made, as other causes were excluded and infectious work-up was normal. Intravenous immunoglobulin and aspirin treatment were started. The boy rapidly improved within 24 hours. Catecholamines were stopped after 2 days, he could be extubated after 3 days, was discharged from intensive care after 4 days and from hospital after 3 weeks. The last available control echocardiography, a few days after hospital stay, showed no sign of coronary aneurysm.

The third child was a 3-year-old boy with a prenatal history of Galien vein aneurism treated by two successful embolisations in the first year of life. He presented with a 1-week history of fever, sore throat, and conjunctival injection. Oral amoxicillin and clavulanic acid treatment was started; however, the boy's clinical state worsened, and therefore he was admitted to the hospital for intravenous antibiotic treatment. Laboratory studies showed signs of important systemic inflammation, with an elevated C-reactive protein (480 milligrams per deciliter), 
elevated white blood cell count $\left(21.4 \times 10^{9}\right.$ per deciliter) with $39 \%$ of immature granulocytes. His serum albumin was low (26 grams per litre). There was no sign of organ dysfunction and troponin was normal during the entire stay in the intensive care unit (Table 2). The chest X-ray showed an enlarged heart and the echocardiography showed pericardial effusion. The boy was referred to the paediatric intensive care unit. He progressively showed signs of tamponade, thus making drainage necessary. Approximately 50 to 60 millilitres of exudate was removed, and a drain was left in the pericardia. A biopsy was also conducted, showing pericarditis. In spite of the drainage, haemodynamic instability persisted and he needed catecholamine. On echocardiography, coronary aneurysms were described with positive z-scores (Table 1), and systolic function was normal - with an ejection fraction of $73 \%$ after drainage and $58 \%$ before drainage - as was diastolic function. Coronary aneurysms, in association with fever, sore throat, and conjunctival injection, made the diagnosis of Kawasaki disease very likely. Intravenous immunoglobulin and aspirin treatment were introduced. The course was complicated by a thrombus of the superior caval vein, on the third day of the stay. $\mathrm{He}$ was treated with alteplase (1 milligram per kilogram over 3 hours), and subsequently he developed cerebral haemorrhage with signs of intracranial hypertension. Despite surgical and medical treatment, the child died on day 7 after admission to intensive care.

\section{Discussion}

These three children presented haemodynamic instability and respiratory failure due to Kawasaki disease. They had severe vascular leakage and hypoalbuminaemia, with pleural and pericardial effusions and ascites. The shock was probably due to an important inflammatory state and vascular leakage, as none of them showed signs of cardiac dysfunction on echocardiography.

Kawasaki disease is a systemic vasculitis; however, inflammatory lesions have been described in other organs, including the heart, the lungs, the haematopoietic and the nervous systems. This inflammation leads to an exudative oedema and increased vascular permeability. ${ }^{6}$ Terai et al worked on the impact and physiopathology of inflammation and vascular leakage in Kawasaki disease. ${ }^{7,8}$ The increased vascular permeability in the acute phase of Kawasaki disease is in relation with the elevation of vascular endothelial growth factor expression. Low serum albumin may be due to the increased production of vascular endothelial growth factor and consecutive increased vascular permeability. Furthermore, they found a direct relation between the severity of oedema and the development of coronary aneurysms. They concluded that vascular leakage may be a key feature of the physiopathology of Kawasaki disease. Consequently, the vascular leakage and inflammatory state could explain a great part of the severity of the disease in our three children.

Owing to the fact that the diagnosis of this disease is infrequent in the paediatric intensive care unit, and that the way of presentation with shock may mimic toxic shock syndrome or sepsis, there is a risk of delayed diagnosis, and therefore delayed treatment. In the report of eight patients admitted for toxic shock syndrome, Wiesenthal and Todd ${ }^{9}$ described one possible case of Kawasaki disease, revealed by coronary aneurysms on control echocardiography. Dominguez et $\mathrm{al}^{10}$ published the first English-written case-control study of patients with Kawasaki disease presenting with shock. They reviewed 14 paediatric intensive care unit children with discharge diagnosis of Kawasaki disease. The most common diagnosis at admission was toxic shock syndrome or septic shock. These children were mainly admitted to the paediatric intensive care unit because of fluid-refractory hypotension and the need for inotropic support, as did our three patients. Interestingly, they found a significant elevation in immature granulocytes and C-reactive protein. Albumin was also significantly lower in the children admitted to the paediatric intensive care unit compared with their control population. We also noticed these laboratory perturbation in our children, which is a sign of important inflammatory state. However, in contrast to their results, our children did not present with renal failure, low platelet count, or coagulopathy. High blood urea nitrogen values of our children at admission were rapidly corrected with fluid replacement; however, creatinine stayed within the normal range and our children did not show any other organ dysfunction.

Cardiac echocardiography of all three children showed coronary artery dilatations. Troponin values were normal to slightly elevated, showing some myocardial inflammation; however, all three children had good systolic and diastolic function, and therefore the shock was not due to myocardial dysfunction.

\section{Conclusion}

Although the diagnosis of Kawasaki disease is rare in the paediatric intensive care unit, the disease can mimic septic shock or toxic shock syndrome. Therefore, clinicians should carefully look for clinical signs of the disease and conduct an echocardiography whenever there is a doubt. Shock in Kawasaki disease can be present even with normal myocardial function, because of severe inflammation and vascular leakage. 


\section{References}

1. Newburger JW, Takahashi M, Gerber MA, et al. Diagnosis, treatment, and long-term management of Kawasaki disease: a statement for health professionals from the Committee on Rheumatic Fever, Endocarditis and Kawasaki Disease, Council on Cardiovascular Disease in the Young, American Heart Association. Circulation 2004; 110: 2747-2771.

2. Cha S, Yoon M, Ahn Y, Han M, Yoon KL. Risk factors for failure of initial intravenous immunoglobulin treatment in Kawasaki disease. J Korean Med Sci 2008; 23: 718-722.

3. Gamillscheg A, Zobel G, Karpf EF, et al. Atypical presentation of Kawasaki disease in an infant. Pediatr Cardiol 1993; 14: 223-226.

4. Hamada H, Terai M, Honda T, Kohno Y. Marked pleural and pericardial effusion with elevated Vascular Endothelial Growth Factor production: an uncommon complication of Kawasaki disease. Pediatr Int 2005; 47: 112-114.

5. Sittiwangkul R, Pongprot Y. Large pleural effusion: an unusual manifestation of Kawasaki disease. Clin Pediatr (Phila) 2004; 43: 389-391.

6. Amano S, Hazama F, Kubagawa H, Tasaka K, Haebara H, Hamashima Y. General pathology of Kawasaki disease. On the morphological alterations corresponding to the clinical manifestations. Acta Pathol Jpn 1980; 30: 681-694.

7. Terai M, Honda T, Yasukawa K, Higashi K, Hamada H, Kohno Y. Prognostic impact of vascular leakage in acute Kawasaki disease. Circulation 2003; 108: 325-330.

8. Yasukawa K, Terai M, Shulman ST, et al. Systemic production of vascular endothelial growth factor and fms-like tyrosine kinase-1 receptor in acute Kawasaki disease. Circulation 2002; 105: 766-769.

9. Wiesenthal AM, Todd JK. Toxic shock syndrome in children aged 10 years or less. Pediatrics 1984; 74: 112-117.

10. Dominguez SR, Friedman K, Seewald R, Anderson MS, Willis L, Glode MP. Kawasaki disease in a pediatric intensive care unit: a case-control study. Pediatrics 2008; 122: e786-e790. 